\title{
Angiopoietin-3 overexpression in tobacco smoke-induced mouse lung tumors and its relation to vitamin $E$ intervention
}

\author{
SUOLIAN ZHANG ${ }^{1 *}$, ZHAOLI CHEN $^{2 *}$, JIE YANG $^{3 *}$, GUOFAN ZHAO $^{1}$, MIN JIN $^{2}$, ZHIQIANG SHEN $^{2}$, \\ JINGFENG WANG ${ }^{2}$, ZHIGANG QIU ${ }^{2}$, XINWEI WANG ${ }^{2}$ and JUN-WEN LI $^{2}$ \\ ${ }^{1}$ Tianjin Medical University, 22 Qixiangtai Road, Tianjin 300070; ${ }^{2}$ Institute of Environment and Health, No.1 Dali Road, \\ Tianjin 300050; ${ }^{3}$ Chinese Center for Disease Control and Prevention, Beijing 100050, P.R. China
}

Received March 28, 2008; Accepted May 27, 2008

DOI: $10.3892 / \mathrm{mmr} 00000020$

\begin{abstract}
Animal studies have shown that tobacco smoke can induce lung cancer in mice, and that the intake of Vitamin E (VE) has a protective effect against its risk. However, the mechanisms of action of VE remain unclear. In this study, DNA microarrays for gene expression profiles of the mouse genome were applied in order to screen for the upregulated genes associated with VE intervention in smoke-induced lung cancer. Real-time PCR was used to validate the screened upregulated angiopoietin-3 gene (Ang-3), and Western blotting was used to investigate the expression of the Ang-3 protein. Our results demonstrate that smoking and VE intervention involve 621 upregulated genes, including oncogenes, nononcogenes with clear function and genes with unclear function. Of these, Ang-3 presented high expression in both the smoking and tumor groups. Real-time PCR and Western blotting further indicated that smoking could upregulate the expression of Ang-3; moreover, Ang-3 was overexpressed in lung cancer tissue. VE intervention decreased its expression to some extent. This illustrates that Ang-3 may play an important role in the carcinogenesis and development of smoke-induced lung cancer, and could also be a target in lung cancer treatment.
\end{abstract}

\section{Introduction}

Lung cancer presents the highest incidence and mortality of all malignancies (1-3). Epidemiological surveys and animal studies have illustrated that smoking tobacco is the main cause of lung cancer (4-6). Chemoprevention, particularly antioxidant intervention, may prove an effective approach to reducing the incidence of lung cancer; however, epidemiological surveys have demonstrated that antioxidant intervention

Correspondence to: Dr Jun-Wen Li, Institute of Environment and Health, No.1 Dali Road, Tianjin 300050, P.R. China

E-mail: junwen9999@hotmail.com

${ }^{*}$ Contributed equally

Key words: angiopoietin-3, overexpression, lung tumor, tobacco smoke, mouse in the prevention of lung cancer has significally different, even counterproductive, outcomes (7-11). By means of an animal study, we validated that vitamin E (VE) can significantly reduce the incidence and number of tumors in lung cancer (12). However, the mechanisms of its action remain unclear (12). Currently, an increasing number of studies indicate that lung cancer may be associated with maladjustment in the regulation of multiple gene expression (13-16). Studies on these genes not only assist in clarifying the mechanisms of carcinogenesis, but also screen for important molecular markers of lung cancer, laying the foundations for the diagnosis, treatment and prevention of tumors. However, traditional techniques are inadequate for the effective analysis of gene expression in the whole genome or for the identification of new genes. DNA microarrays can be used to monitor gene expression in the whole genome (17-19), clarify the mechanisms of smokinginduced lung cancer and VE intervention, and discover new genes. However, the reproducibility of gene chip assays is relatively poor, and further validation is required.

In this study, a gene chip assay was used to screen whole mouse genome sequences for upregulated genes associated with smoking-induced lung cancer and VE intervention. Realtime FQ PCR was then applied to identify significantly upregulated Angiopoietin (Ang)-3 in tumor samples screened by the assay, and finally Western blotting was used to analyze the protein expression of Ang-3. The study aids in clarifying Ang-3 function, particularly its role in smoking-induced lung cancer.

\section{Materials and methods}

Animals. Approximately 5-week-old male and female Swiss mice weighing 18-20 g were purchased from the Laboratory Animal Center of the Academy of Military Medical Science (Beijing, P.R. China). Twenty-five mice were housed per cage under standardized conditions with free access to pelleted food or test diet and tap water. All studies were performed with the approval of the Experimental Animal Committee at the Institute of Environment and Health.

Intervening effect of vitamin $E$ on passive smoke-induced mouse lung cancer. Mice were subjected to the environmental tobacco smoke (ETS) system, as previously described (4). In brief, they were exposed to a mixture of $89 \%$ sidestream and $11 \%$ mainstream smoke generated by the burning of cigarettes 
Table I. Effect of VE intervention on the incidence and multiplicity of smoke-induced lung cancer.

\begin{tabular}{lccc}
\hline Group & No. & $\begin{array}{c}\text { Lung cancer } \\
\text { multiplicity }\end{array}$ & $\begin{array}{c}\text { Lung cancer } \\
\text { incidence }(\%)\end{array}$ \\
\hline Control & 25 & $0.18 \pm 0.07$ & 16.2 \\
TS & 25 & $1.63 \pm 0.38^{\mathrm{a}}$ & $47.6^{\mathrm{a}}$ \\
TS+VE & 25 & $0.16 \pm 0.08^{\mathrm{b}}$ & $15.0^{\mathrm{b}}$
\end{tabular}

TS, mice exposed to ETS; T, mice with ETS-induced tumors; VE+TS, mice exposed to ETS with VE intervention; aCompared to the control group, $\mathrm{p}<0.05$; ${ }^{\mathrm{a}} \mathrm{Compared}$ to the TS group, $\mathrm{p}<0.05$.

(Hongmei brand, Yuxi Hongta Group, Yunnan, P.R. China; purchased from the supermarket; tar content $15 \mathrm{mg}$, nicotine content $1.2 \mathrm{mg}$ ). Chamber atmospheres were monitored for nicotine, $\mathrm{CO}$ and total suspended particulates (TSPs). Within the exposure chambers, all cages were periodically rotated so as to occupy all possible locations within the exposure chambers at least once. After an initial acclimatization period of 5 weeks involving increasing concentrations of tobacco smoke within the chamber, tobacco smoke concentrations used for the individual experiments contained $50-150 \mathrm{mg} / \mathrm{m}^{3}$ TSP. Nicotine, CO and TSP concentrations for the individual experiments are listed in Table I, and data not shown.

One hunded and fifty male and female mice were randomly divided into three groups: normal controls, mice exposed to tobacco smoke (TS), and mice exposed to tobacco smoke plus VE (VE+TS) $(n=25)$. Mice were exposed to smoke for $6 \mathrm{~h}$ each day, 5 days a week for 5 months, followed by recovery for 4 months. VE was administered via their diet at a dose of $100 \mathrm{mg} / \mathrm{kg} /$ day.

Twelve lung tissue samples snap-frozen in liquid nitrogen were taken from each of the following groups: the control group, the TS group, the VE+TS group, and from the tumor (T) group of mice with ETS-induced tumors.

Pathological testing. Towards the end of the smoking challenge experiments, mice were anesthetized and peripheral blood was collected via orbital sinus venipuncture. To analyze the incidence and multiplicity of lung cancer, lungs were harvested and half the samples were randomly selected for fixation in Tellyesniczky's solution (70\% ethanol, formaldehyde and acetic acid at a ratio of 20:5:3). The remaining samples were snap-frozen in liquid nitrogen. Tumors were counted with an anatomic microscope. Lung samples with tumor nodules were embedded in paraffin, sectioned and stained using H\&E for pathological analysis.

cDNA microarray analysis. Five normal lung tissue samples were collected from mice without tumors in the control, ETS and VE+TS groups, each. Tumor tissue (without normal lung tissue) was collected from the TS mice. Total-RNA was extracted from 50-100 mg of a mixture of mice lung tissues from each group using TRIzol (Qiagen, Chatsworth, CA, USA), then further purified using RNeasy columns and ribonuclease-free deoxyribonuclease I (Qiagen) according to the manufacturer's instructions. Analysis of gene expression was carried out with MOE430 A\&B gene chips (Affymetrix, Santa Clara) from Shanghai Genechip Co. (Shanghai, P.R. China). Preparation and hybridization of cDNA probes were performed as previously described (20). Standard Affymetrix protocols (www.affymetrix.com/index.affx) were used to generate RNA probes from $5 \mu \mathrm{g}$ of extracted RNA. The samples were hybridized to the MOE430 A\&B chips on a gene chip system (Affymetrix) at the Shanghai Genechip Co. (www. shbiochip.com/indexe.html) according to the manufacturer's instructions. All data were analyzed according to previously described procedures (21-24). To identify genes differentiallyregulated by ETS with a high level of confidence (ratio $\geq 1$.0fold change, $<5 \%$ false discovery rate), the significance analysis of microarray (SAM) (22) was used to compare expression levels in the control, TS and VE+TS samples. Gene function was analyzed based on available published data in the PubMed (www.ncbi.nlm.nih.gov/entrez) and NetAffx databases.

Real-time FQ PCR. cDNA was reverse transcribed using the First Strand cDNA Synthesis Kit (Fermat) according to the manufacturer's protocol. Real-time PCR was conducted using SYBR $^{\circledR}$ Premix Ex Taq ${ }^{\text {TM }}$ kit (Takara, Kyoto, Japan) on an iCycler iQTM real-time PCR detection system (Bio-Rad, Hercules, CA, USA). Data were analyzed using the $\triangle \triangle C T$ method as previously described (25). Primers used for the Ang-3 reactions were 5'-AGG TGG CTG GAC CCT CAT CCA G-3' (forward) and 5'-CCC AGC CAG TGC TCT CTG GCC-3' (reverse) (accession number: AF113707). Primers used for the $\beta$-actin reactions were 5'-GAC AGG ATG CAG AAG GAG A-3' (forward) and 5'-GCT GGA AGG TGG ACA GTG AG-3' (reverse) (accession no.: NM_009609.2). PCR products were obtained by Ang-3 and $\beta$-actin reactions at 110 and $207 \mathrm{bp}$, respectively.

Western blot analysis. Total proteins were obtained for Western blot analysis by the lysis of lung tissues in buffer containing $20 \mathrm{mM}$ Tris, $150 \mathrm{mM} \mathrm{NaCl}, 1 \%$ NP-40, 1\% SDS, $5 \%$ glycerol and a Complete mini protease inhibitor cocktail tablet (Roche, NJ, USA). Proteins (50 $\mu \mathrm{g}$ ) were separated on $12 \%$ SDS-polyacrylamide gel and transferred to nitrocellulose filters. These were then blocked in Tris-buffered saline with Tween buffer containing 5\% skimmed milk and incubated overnight with a monoclonal antibody to Ang-3 (Santa Cruz), followed by the addition of horseradish peroxidase-linked anti-mouse IgG (Zhongshan Biotechnology Co., Ltd., Beijing, P.R. China) and ECL visualization of the bands.

Statistical analysis. The statistical significance of the differences between the treatment groups was determined using the standard computerized statistical program SPSS 11.5. $\mathrm{p} \leq 0.05$ was considered significant.

\section{Results}

Incidence and multiplicity of lung cancer. The natural incidence of lung cancer in the $\mathrm{C}$ group was $16 \%$. The incidence and multiplicity of lung cancer in the smoke-exposed groups were significantly higher than in the $\mathrm{C}$ groups $(\mathrm{p}<0.05)$. VE intervention decreased the incidence and multiplicity of lung cancer caused by exposure to smoke $(\mathrm{p}<0.05)$ (Table I). 
Histopathology revealed that all the lung cancer nodules were solid lung adenomas. These adenomas comprised wellcircumscribed areas of proliferating polygonal-to-cuboidal cells, which lined and filled the alveoli, occasionally exhibiting cytoplasmic vacuolization and mucus production. Foci exhibiting hyperchromasia and cytologic and/or nuclear atypia were observed in some adenomas. Normal pulmonary architecture was destroyed, and the adjacent parenchyma was compressed by the lung cancer nodules (Fig. 1, and data not shown).

Gene chip detection and analysis. Eight chips (4x2) exhibiting the gene expression profile of the whole mouse genome were used to detect gene expression in the control, TS, VE+TS and T groups. The upregulation of a gene was determined by comparing the data of the $\mathrm{T}$ group with that of the other groups. As a result of the comparison, 621 upregulated genes (ratio $\geq 1$.0-fold change, $<5 \%$ false discovery rate) were discovered, including 293 genes whose function remains unclear. Among the upregulated genes, the following 7 oncogenes were identified: Cxcl1, Ect2, Fosb, MGC79224, Rab20, Rab27a and Ros1. Other upregulated genes were mainly functional genes participating in the signal transduction pathway, cell cycle regulation, cell adhesion, immune and inflammatory reactions, cell differentiation, metabolism, transcriptional regulation, apoptosis, angiogenesis, hydrolysis of protein and amino acids, DNA repair, phosphorylation, intracellular protein transport, electron transport, cell death, fatty acid biosynthesis, etc.

At a ratio $\geq 2$, only two upregulated oncogenes remained. Of the upregulated genes, 59 were functional genes involved in signal transduction pathways, cell cycle regulation, cell adhesion, immune and inflammatory reactions, cell differentiation, metabolism, transcriptional regulation, hydrolysis of protein and amino acids, etc. There were 60 upregulated genes whose functions remain unclear.

Gene-chip detection results may contain certain errors, and further validation of the upregulated expression of certain genes is therefore required. We selected Ang-3 from among the upregulated genes (Table II) for identification by real-time PCR and Western blotting.

Detection of Ang-3 mRNA expression by real-time FQ PCR. First, statistical analysis using Ang-3 expression data obtained for the female and male mice of each group was performed. No statistically significant differences were found between males and females within each group $(p>0.05)$. Data from the female and male mice were then combined for intergroup comparisons. The results indicate that Ang-3 mRNA expression was markedly higher in the TS, VE+TS and T groups than in the controls $(\mathrm{p}<0.05)$, markedly higher in the $\mathrm{T}$ group than in the TS group $(\mathrm{p}<0.05)$, and markedly higher in the VE+TS group than in the control or TS groups $(\mathrm{p}<0.05)$. Though expression in the VE+TS group was lower than in the $\mathrm{T}$ group, this was not statistically significant $(\mathrm{p}>0.05)$ (Table III).

Expression of Ang-3 protein detected by Western blotting. Ang-3 protein expression was markedly higher in the TS group than in the controls $(\mathrm{p}<0.05)$, markedly higher in the $\mathrm{T}$ group than in the control and TS groups $(\mathrm{p}<0.05)$, and markedly higher in the VE +TS group than in the controls
A

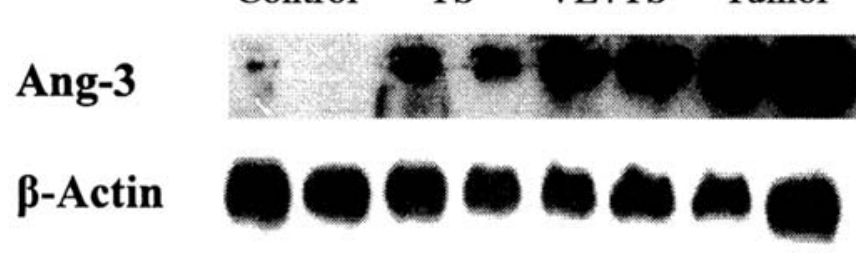

B

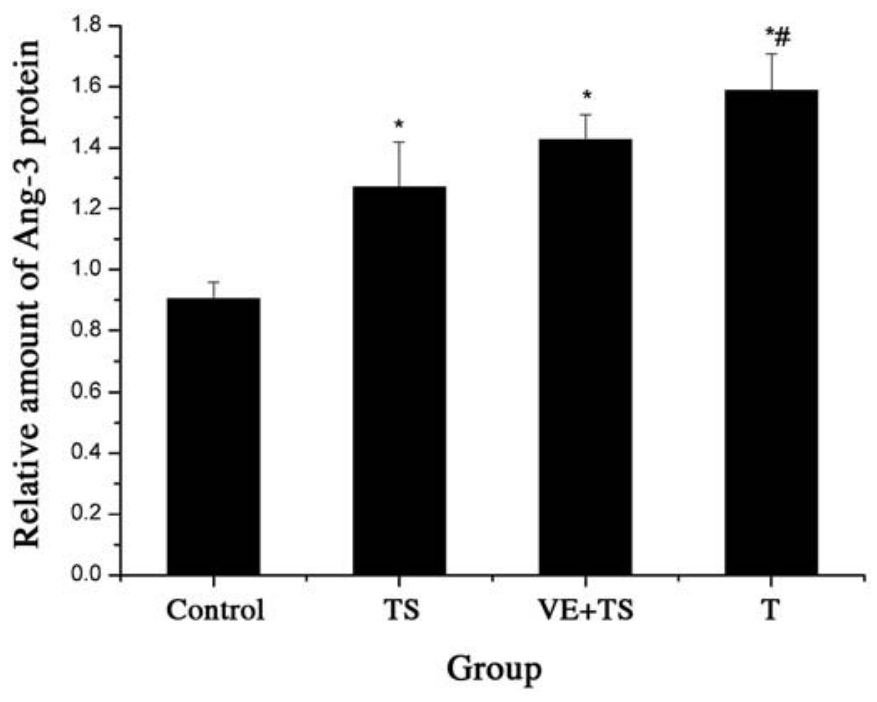

Figure 1. Expression of Ang-3 protein in mouse lung tissues. C, normal controls; TS, mice exposed to ETS; T, mice with ETS-induced tumors; VE+TS, mice exposed to ETS with VE intervention; *compared to controls, $\mathrm{p}<0.05 ;{ }^{*}$ compared to TS, $\left.\mathrm{p}<0.05\right)$.

Table II. Expression of the Ang-3 gene detected by microarray.

\begin{tabular}{lcc}
\hline Group & Accessions & Upregulation rate \\
\hline T vs. control & AF113707 & 2.2 \\
T vs. TS & AF113707 & 1.5 \\
T vs. VE+TS & AF113707 & 5.7 \\
\hline
\end{tabular}

TS, mice exposed to ETS; T, mice with ETS-induced tumors; VE+TS, mice exposed to ETS with VE intervention.

Table III. Expression of Ang-3 mRNA $(x \pm s)$.

\begin{tabular}{lcc}
\hline Group & No. & Relative amount of Ang-3 mRNA \\
\hline Control & 12 & $1.047 \pm 0.344$ \\
TS & 12 & $9.795 \pm 2.952^{\mathrm{a}}$ \\
VE+TS & 12 & $27.634 \pm 15.604^{\mathrm{a}, \mathrm{b}}$ \\
$\mathrm{T}$ & 12 & $30.654 \pm 15.224^{\mathrm{a}, \mathrm{b}}$ \\
\hline
\end{tabular}

TS, mice exposed to ETS; T, mice with ETS-induced tumors; VE+TS, mice exposed to ETS with VE intervention; acompared to controls, $\mathrm{p}<0.05 ;{ }^{\mathrm{b}}$ compared to TS, $\mathrm{p}<0.05$. 
$(p<0.05)$. Though expression in the VE+TS group was lower than in the $\mathrm{T}$ group and higher than in the TS group, this was not statistically significant ( $\mathrm{p}>0.05)$, (Fig. 1).

\section{Discussion}

Cigarette smoking-induced lung cancer and VE intervention might involve the synergistic effect of multiple genes. The results of gene chip detection adequately confirm this notion. The functions of the upregulated genes are mainly participation in signal transduction pathways, cell cycle regulation, cell adhesion, immune and inflammatory reactions, cell differentiation, metabolism, transcriptional regulation, apoptosis, angiogenesis, hydrolysis of protein and amino acids, among others. In addition, there are a large number of upregulated genes whose functions are unclear, which may be prospective new genes. We believe our findings are of significant value, and that further study of the molecular mechanisms involved in smoke-induced lung cancer and VE intervention is warranted.

This study further investigated Ang-3 expression, screened using gene chip detection. Real-time FQ-PCR revealed that Ang-3 mRNA expression was markedly higher in the TS group than in the control group, illustrating that smoking significantly upregulates this gene. Moreover, Ang-3 mRNA expression was highest in the $\mathrm{T}$ group - markedly higher than in the control group and higher than in the TS group - suggesting that this gene might be closely related to tumorigenesis and development. This result conforms to the results of gene chip detection. However, although VE intervention markedly decreased the incidence and number of tumors in smoking-induced lung cancer (12), Ang-3 mRNA expression was not significantly reduced. This indicates that VE prevention of smoking-induced lung cancer is not achieved through regulation of the Ang-3 gene, contrary to the results of gene chip detection, which suggested that VE might reduce Ang-3 expression.

Western blot analysis revealed that Ang-3 protein expression was significantly higher in the TS group than in the control group, demonstrating that smoking not only promotes the expression of Ang-3 mRNA but also accelerates the expression of its protein. Ang-3 protein expression was highest in the T group - markedly higher than in the control and TS groups further illustrating that expression of the Ang-3 gene and its protein might be associated with carcinogenesis and the development of smoke-induced lung cancer. Although VE intervention reduced Ang-3 protein expression as compared to the $\mathrm{T}$ group, it seemingly increased Ang-3 protein expression as compared to the TS group. This conforms to the results of real-time FQ-PCR.

The Ang family comprises four molecules - Ang-1, Ang-2, Ang-3 and Ang-4 (26) - and participates primarily in the regulation of multiple angiogenic growth factors during angiogenesis. A relationship between lung cancer and Ang-1 and Ang-2 has been reported. Wong et al (28) and Reinmuth et al (29) found that Ang-1 presents high expression in normal lung tissue or in the lung cancer tissue of patients with a better prognosis. However, Takahama et al (30) reported that expression of Ang-1, Tie2, vascular endothelial growth factor (VEGF) and CD31 mRNA was significantly higher in tumors than in tumor-adjacent tissue. Most reports indicate that Ang-2 presents high expression in lung cancer, particularly in nonsmall cell lung carcinomas (28,31-33). In contrast to Ang-1, positive expression of Ang-2 might indicate a poor prognosis for lung cancer (34).

Ang-3 is a newly-discovered Ang family member (26). Mouse Ang-3 is located on chromosome 2. Its complete length is $1530 \mathrm{bp}$, and it has an open reading frame coding 509 amino acids. To date, Ang-3 expression has only been observed in lung cells and human umbilical vein endothelial cells (HUVECs). VEGF can upregulate Ang-3 expression and downregulate Ang-2 expression in HUVECs (35). Reports have confirmed that Ang-3 and Ang-2 can compete with Ang-1 to bind to Tie-2, thereby impeding Ang-1-induced Tie-2 phosphorylation $(36,37)$. However, there is limited information regarding the biological function of Ang-3, and even less information regarding its relationship with tumors. Xu et al (38) reported that Ang-3 overexpression inhibited lung metastasis in Lewis lung carcinoma and mammary carcinoma by suppressing tumor angiogenesis and promoting tumor cell apoptosis. Although this suggests that Ang-3 might inhibit cancer metastasis, it cannot explain the relationship between Ang-3 and lung cancer. Thijssen et al (39) introduced ovarian carcinoma cells into nude mice and obtained a xenograft tumor. After detection, they found that Ang-3 was upregulated in nontumor cells. Thus far, there have been no reports regarding the relationship between Ang-3 and lung carcinogenesis and development. For the first time, our study proves that smoking can promote the expression of Ang-3 mRNA and protein, and that Ang-3 is overexpressed in smoking-induced lung cancer.

In this study, a DNA microarray of the gene expression profile of the whole mouse genome, real-time FQ PCR and Western blotting were used to prove that smoking can significantly upregulate the expression of Ang-3 mRNA and protein. This expression was highest in tumor tissue, indicating that Ang-3 might promote carcinogenesis and the development of lung cancer. However, the relationship between Ang-3 and smoking, as well as the expression of Ang-3 in lung cancer, needs to be tested and validated by clinical trials. If Ang-3 exhibits high expression in human lung cancer, it could serve as an indicator for lung cancer prognosis in a similar fashion to Ang-1 and Ang-2. In the meantime, it may become a target for lung cancer treatment. However, no clear relationship between VE intervention, smoking-induced lung cancer prevention and Ang-3 has been found. This provides the basis for further investigation of the function of Ang-3 and its role in the carcinogenesis of lung cancer.

\section{Acknowledgements}

We thank Yufei Zheng for assistance with the preparation of experiments, and Jing-Yu Wei for vitamin analysis.

\section{References}

1. Jemal A, Siegel A, Ward E, Murray T, Xu J, Smigal C and Thun MJ: Cancer statistics, 2006. CA Cancer J Clin 56: 106-130, 2006.

2. American Cancer Society (ACS): Cancer Facts and Figures 2006. American Cancer Society, Atlanta, 2006.

3. Yang L, Li L, Chen Y and Parkin DM: Mortality time and the incidence and mortality estimation and projection for lung cancer in China. Chin J Lung Cancer (in Chinese) 8: 274-278, 2005.

4. Witschi HP and Espiritu I: Development of tobacco smokeinduced lung tumors in mice fed Bowman-Birk protease inhibitor concentrate (BBIC). Cancer Lett 183: 141-146, 2002. 
5. Thun MJ, Henley SJ and Calle EE: Tobacco use and cancer: an epidemiologic perspective for geneticists. Oncogene 21: 7307-7325, 2002.

6. International Early Lung Cancer Action Program Investigators, Henschke CI, Yip R and Miettinen OS: Women's susceptibility to tobacco carcinogens and survival after diagnosis of lung cancer. JAMA 296: 180-184, 2006.

7. The Alpha-Tocopherol, Beta Carotene Cancer Prevention Study Group: The effect of vitamin $\mathrm{E}$ and beta carotene on the incidence of lung cancer and other cancers in male smokers. N Engl J Med 330: 1029-1035, 1994.

8. Lonn E, Bosch J, Yusuf S, Sheridan P, Pogue J, Arnold JM, Ross C, Arnold A, Sleight P, Probstfield J and Dagenais GR (HOPE and HOPE-TOO Trial Investigators): Effects of long-term vitamin E supplementation on cardiovascular events and cancer: a randomized controlled trial. JAMA 293: 1338-1347, 2005.

9. Menkes MS, Comstock GW, Vuilleumier JP, Helsing KJ, Rider AA and Brookmeyer R: Serum beta-carotene, vitamins A and E, selenium, and the risk of lung cancer. N Engl J Med 315: 1250-1254, 1986

10. Yano T, Uchida M, Yuasa M, Murakami A, Hagiwara K and Ichikawa T: The inhibitory effect of vitamin $\mathrm{E}$ on K-ras mutation at an early stage of lung carcinogenesis in mice. Eur J Pharmacol 323: 99-102, 1997.

11. Woodson K, Tangrea JA, Barrett MJ, Virtamo J, Taylor PR and Albanes D: Serum a-Tocopherol and subsequent risk of lung cancer among male smokers. J Natl Cancer Inst 91: 1738-1744, 1999.

12. Yang J, Wang L, Chen Z, Shen ZQ, Jin M, Wang XW, Zheng Y, Qiu Z, Wang J and Li JW: Antioxident intervention of smokinginduced lung tumor in mice by vitamin $\mathrm{E}$ and Quercetin. BMC cancer (revised), 2008

13. Devita VT, Hellman S and Rosenberg S: Cancer: Principles and Practice of Oncology. 7th edition. Lippincott Williams \& Wilkins, 2005.

14. Keum JS, Kong G, Yang SC, Shin DH, Park SS, Lee JH and Lee JD: Cyclin D1 overexpression is an indicator of poor prognosis in resectable non-small cell lung cancer. Br J Cancer 81: 127-132, 1999.

15. Cai YC, Yang GY, Nie Y, Wang LD, Zhao X, Song YL, Seril DN, Liao J, Xing EP and Yang CS: Molecular alterations of p73 in human esophageal squamous cell carcinomas: loss of heterozygosity occurs frequently, loss of imprinting and elevation of p73 expression may be related to defective p53. Carcinogenesis 21: 683-689, 2000.

16. Dammann R, Li C, Yoon JH, Chin PL, Bates S and Pfeifer GP: Epigenetic inactivation of a RAS association domain family protein from the lung tumour suppressor locus 3p21.3. Nat Genet 25: 315-319, 2000.

17. De Risi J, Penland L, Brown PO, Bittner ML, Meltzer PS, Ray M, Chen Y, Su YA and Trent JM: Use of a cDNA microarray to analyze gene expression patterns in human cancer. Nat Genet 14: 457-460, 1996

18. Lockhart DJ, Dong H, Byrne MC, Follettie MT, Gallo MV, Chee MS, Mittmann M, Wang C, Kobayashi M, Horton $\mathrm{H}$ and Brown EL: Expression monitoring by hybridization to high-density oligonucleotide arrays. Nat Biotechnol 14: 1675-1680, 1996.

19. Schena M, Shalon D, Davis RW and Brown PO: Quantitative monitoring of gene expression patterns with a complementary DNA microarray. Science 270: 467-470, 1995

20. Glover CH, Marin M, Eaves CJ, Helgason CD, Piret JM and Bryan J: Meta-analysis of differentiating mouse embryonic stem cell gene expression kinetics reveals early change of a small gene set. PLoS Comput Biol 2: E158, 2006.

21. Tusher VG, Tibshirani R and Chu G: Significance analysis of microarrays applied to the ionizing radiation response. Proc Natl Acad Sci USA 98: 5116-5121, 2001.

22. Irizarry RA, Bolstad BM, Collin F, Cope LM, Hobbs B and Speed TP: Summaries of Affymetrix GeneChip probe level data. Nucleic Acids Res 31: E15, 2003
23. Gautier L, Cope L, Bolstad BM and Irizarry RA: AaffyAnalysis of Affymetrix GeneChip data at the probe level. Bioinformatics 20 : 307-315, 2004

24. Gentleman RC, Carey VJ, Bates DM, Bolstad B, Dettling M, Dudoit S, Ellis B, Gautier L, Ge Y, Gentry J, Hornik K, Hothorn T, Huber W, Iacus S, Irizarry R, Leisch F, Li C, Maechler M, Rossini AJ, Sawitzki G, Smith C, Smyth G, Tierney L, Yang JY and Zhang J: Bioconductor: open software development for computational biology and bioinformatics. Genome Biol 5: R80, 2004.

25. Livak KJ and Schmittgen TD: Analysis of relative gene expression data using real-time quantitative PCR and the $2-\Delta \Delta C T$ method. Methods 25: 402-408, 2001.

26. Valenzuela DM, Griffiths J, Rojas J, Aldrich TH, Jones PF, Zhou H, McClain J, Copeland NG, Gilbert DJ, Jenkins NA, Huang T, Papadopoulos N, Maisonpierre PC, Davis S and Yancopoulos GD: Angiopoietin 3 and 4: diverging gene counterparts in mouse and humans. Proc Natl Acad Sci USA 96: 1904-1909, 1999.

27. Folkman J: Angiogenensis in cancer, vascular, rheumatoid and other disease. Nat Med 1: 27-31, 1995.

28. Wong MP, Chan SY, Fu KH, Leung SY, Cheung N, Yuen ST and Chung LP: The angiopoietins, tie2 and vascular endothelial growth factor are differentially expressed in the transformation of normal lung to non-small cell lung carcinomas. Lung Cancer 29: $11-22,2000$

29. Reinmuth N, Piegelbrock E, Raedel M, Fehrmann N, Hintelmann H, Wagner R, Berdel WE, Thomas M, Freitag L and Mesters RM: Prognostic significance of vessel architecture and vascular stability in non-small cell lung cancer. Lung Cancer 55: $53-60,2007$

30. Takahama M, Tsutsumi M, Tsujiuchi T, Nezu K, Kushibe K, Taniguchi S, Kotake Y and Konishi Y: Enhanced expression of Tie2, its ligand angiopoietin-1, vascular endothelial growth factor and CD31 in human non-small cell lung carcinomas. Clin Cancer Res 5: 2506-2510, 1999.

31. Takanami I: Overexpression of Ang-2 mRNA in non-small cell lung cancer: association with angiogenesis and poor prognosis. Oncol Rep 12: 849-853, 2004.

32. Park JH, Park KJ, Kim YS, Sheen SS, Lee KS, Lee HN, Oh YJ and Hwang SC: Serum angiopoietin-2 as a clinical marker for lung cancer. Chest 132: 200-206, 2007.

33. Xing L, Zhang Z and Xu Y: Expression of angiopoietin-2 gene in non-small cell lung cancer. J Huazhong Univ Sci Technolog Med Sci 23: 362-364, 2003

34. Tanaka F, Ishikawa S, Yanagihara K, Miyahara R, Kawano Y, Li M, Otake $\mathrm{Y}$ and Wada $\mathrm{H}$ : Expression of angiopoietins and its clinical significance in non-small cell lung cancer. Cancer Res 62: 7124-7129, 2002.

35. Nishimura M, Miki T, Yashima R, Yokoi N, Yano H, Sato Y and Seino S: Angiopoietin-3, a novel member of the angio-poietin family. FEBS Lett 448: 254-256, 1999.

36. Maisonpierre PC, Suri C, Jones PF, Bartunkova S, Wiegand SJ, Radziejewski C, Compton D, McClain J, Aldrich TH, Papadopoulos N, Daly TJ, Davis S, Sato TN and Yancopoulos GD: Angiopoietin-2, a natural antagonist for Tie2 that disrupts in vivo angiogenesis. Science 277: 55-60, 1997.

37. Holash J, Maisonpierre PC, Compton D, Boland P, Alexander CR, Zagzag D, Yancopoulos GD and Wiegand SJ: Vessel cooption, regression and growth in tumors mediated by angiopoietins and VEGF. Science 284: 1994-1998, 1999.

38. Xu Y, Liu YJ and Yu Q: Angiopoietin-3 inhibits pulmonary metastasis by inhibiting tumor angiogenesis. Cancer Res 64 6119-6124, 2004

39. Thijssen VL, Brandwijk RJ, Dings RP and Griffioen AW: Angiogenesis gene expression profiling in xenograft models to study cellular interactions. Exp Cell Res 299: 286-293, 2004. 